\title{
Investigating the Environmental and the Energy Saving Behavior among School Principals through Classification Algorithms
}

\author{
Stamatios Ntanosa, Grigorios L. Kyriakopoulos, ,*, Theodoros Anagnostopoulosc, \\ Theodoros Xanthopoulos ${ }^{c}$, Christos Kytagias ${ }^{c}$, Dimitrios Drosos ${ }^{a}$
}

${ }^{a}$ School of Business, Economics and Social Sciences, Department of Business Administration, University of West Attica, 250 Thivon \& P. Ralli str, 12244 Egaleo, Greece.

${ }^{b}$ School of Electrical and Computer Engineering, Electric Power Division, Photometry Laboratory, National Technical University of Athens, 15780 Athens, Greece.

${ }^{c}$ Department of Business Administration, DigiT.DSS.Lab, University of West Attica, 250 Thivon \& P. Ralli str, 12244 Egaleo, Greece.

\begin{abstract}
Buildings are a significant energy consumption point since they account for $40 \%$ of the total energy demand and around $1 / 3$ of greenhouse gas emissions. Energy-saving measures applied in the residential sector have led to a reduction in energy consumption during the last decade. On the contrary, such measures have not been widely applied in school buildings, although education is the second-largest energy consumer in the service sector. This paper aims to assess school principals' perceptions concerning energy saving and the environment since they are responsible for promoting energy-saving measures and investments and inspiring students and school personnel towards environmentally friendly behavior. Using survey data from Greek schools, we applied predictive classification models to locate the most critical variables that drive principals' perceptions of energy upgrading and energy-saving actions at school. Results revealed that the positive environmental perceptions of principals, the level of knowledge on Renewable Energy Sources (RES) and the active energy-saving behavior are related to energy-saving actions and energy upgrading in school environment. Furthermore, the creation of more RES oriented courses is related to positive energy-saving behavior and actions. Thus, emphasis should be put on educating and informing the school principals concerning RES technologies and energy-saving options since they are critical players in applying energy-saving measures in school buildings.
\end{abstract}

Keywords: environmental behavior, school environment, renewable energy, energy-saving, school building, classification algorithms

Article history: Received: $26^{\text {th }}$ Nov 2021; Revised: $2^{\text {nd }}$ January 2022; Accepted: $15^{\text {th }}$ January 2022; Available online: $30^{\text {th }}$ January 2022 How to cite this article: Ntanos, S., Kyriakopoulos, G.L, Anagnostopoulos, T., Xanthopoulos, T., Kytagias, C., Drosos, D. (2022) Investigating the Environmental and the Energy Saving Behavior among School Principals through Classification Algorithms. International Journal of Renewable Energy Development, 11(2), 449-461

https://doi.org/10.14710/ijred.2022.43007

\section{Introduction}

Energy production and consumption are integral parts of modern economies, supporting human development as the prosperity of societies is so interconnected with energy (Skordoulis et al., 2020a; Acharya and Adhikari, 2021). Today, about $81 \%$ of the world's primary energy is generated from fossil fuels, with oil accounting for $31.9 \%$, coal for $27.1 \%$ and gas for $22.1 \%$ (Fateh and Zrelli, 2019). In recent years, a transformation of energy modes of production and consumption has been modelled on a "sustainable development" vision. The application of energy-saving technologies and RES, especially in residential buildings, led to a gradual decrease in energy consumption from 2008 to 2016 (Odyssee-Mure Project, 2021). The impact and the viability of renewable energy investments and the vital role of corporate environmental responsibility are significant areas of research (Zografidou et al., 2017; Giannarakis et al., 2018). In addition to delays and setbacks, an international effort is being made to tackle climate change and change the mix of fuels and technologies (Diakoulaki, 2014).

Education is the second-largest consumer of energy in the service sector. School buildings are significant points of energy consumption. In the European Union (EU) context, buildings alone are responsible for $40 \%$ of total energy consumption, $60 \%$ of electricity consumption and $36 \%$ of greenhouse gas emissions. While new buildings generally require less than $3-5 \mathrm{lt} / \mathrm{m}^{2} /$ year of heating oil, older buildings require an average of $25 \mathrm{lt} / \mathrm{year}$. Some energy-intensive buildings require even 60 litres $/ \mathrm{m}^{2} /$ year. $35 \%$ of EU buildings are over 50 years old (Doukas et al., 2017). Similarly, in the United States, the ASHRAE's Building Energy Quotient (bEQ) program is an eco-

* Correspondence author: gregkyr@chemeng.ntua.gr 
Citation: Ntanos, S., Kyriakopoulos, G.L, Anagnostopoulos, T., Xanthopoulos, T., Kytagias, C., Drosos, D. (2022) Investigating the Environmental and the Energy Saving Behavior among School Principals through Classification Algorithms. International Journal of Renewable Energy Development, 11(2), 449-461, doi: 10.14710/ijred.2022.43007 450

labelling program of reducing building operating costs in the industry sector.

The transposition of the European Building Efficiency Directive (EPBD) in Greece entered in 2008. Greece has no previous experience with mandatory energy efficiency labelling buildings and energy performance certificates (EPCs) in the pre-Greek era. However, new and older buildings necessitate major renovations to obtain a Category-B building permit (Dascalaki et al., 2013).

Improving energy efficiency in buildings is one of the top priorities worldwide. However, little research has focused on linking education policies and energy demand. Therefore, in exploring the role of energy policies in education, researchers need to determine those factors that drive energy policies. To this end, various measures are available, and the decision-maker faces a multiobjective decision problem that must be offset by deciding about energy, finance, and other factors to make a good choice. (Diakaki et al., 2013).

This paper focuses on the role of the school unit principal as a decision-maker concerning energy-saving action by exploring the environmental perceptions and energy-saving behaviour and unveiling what motivates the application of energy upgrading and the positive environmental perceptions.

More specifically, the objective of this research is to locate the most important predictive variables that are associated with each of the five following statements:

- The importance of providing RES oriented education in schools.

- The teachers' role towards energy saving at the school environment.

- The students' role towards energy saving at the school environment.

- The teachers' role in raising awareness on RES.

- The use of energy upgrading and energy-saving actions at school

To focus on the most important variables that are associated with each of the previous objectives, data were collected by questionnaire from schools of all education levels for the case of Greece. Predictive classification models were used, and we located the most important variables for each factor.

\section{Literature review}

The global environment is directly affected by buildings lifecycle since the design and the ownership of buildings play an essential role in shaping current and future environmental impacts. In particular, the British government had set targets for reducing environmental impacts, including carbon emissions from energy production and use, through the White Paper on Energy. In this research context, many critical factors are created in the building process, and everyone has a role that can affect the chances of using alternative energy technologies. Increased use of embedded alternative green energy technologies is important because, among other things, they meet UK policies and provide social, economic, mechanical, and environmental benefits (Cooke et al., 2007).

The improvement of energy efficiency at buildings in Europe plays a determining role in achieving the EU targets for 2020 and 2030 and meeting the long-term goals for a low-carbon economy roadmap 2050. Directives 2010/31/EU (Energy Efficiency Directive for BuildingsEPBD) and 2012/27/EU (Energy Efficiency Directive EED) introduced specific measures to improve the energy efficiency of the European building stock. Although the directives as mentioned above have recently been amended by directives 2018/844 and 2018/2002, respectively, the main objective of the EPDB is near-zero energy buildings (nZEBs) since "almost zero or meagre amount of energy required must be covered to a very significant degree by energy from renewable sources, including energy from renewable sources produced on-site or nearby" (Pallis et al., 2019). Moreover, the reduction of energy consumption of buildings is one of the essential pillars of the broader goal to improve energy efficiency, and this is evidenced by a series of provisions concerning the building sector (Doukas et al., 2017).

School buildings are unique and special types of buildings. Its successful operation depends on many parameters such as visual comfort, reflection, indoor quality, air quality, lack of colours or not, uniformity of lighting, the satisfaction of teaching staff, ventilation, how lighting affects children's behavior, the orientation of the building and the energy consumption. The almost zero energy building policy (nZEB) is vital for the EU and now applies to school buildings (Doulos et al., 2019). Pereira et al. (2014) examined energy consumption in school buildings and reported a range of primary energy consumption from $86 \mathrm{kWh} / \mathrm{m}^{2}$ to $272 \mathrm{kWh} / \mathrm{m}^{2}$ and a range of annual consumption reduction of electricity from 18 $\mathrm{kWh} / \mathrm{m}^{2}$ to $66 \mathrm{kWh} / \mathrm{m}^{2}$.

School buildings are significant to society since these represent a significant part of the building stock, and the number of children attending schools is immense. There are more than 100 million in Europe. However, in the design of school buildings, obtaining the proper environment is often not considered a priority. Existing school buildings are often lacking systems that optimize energy consumption. In recent decades, several educational buildings have been built with respect for environmental protection and rational energy use (Zeiler and Boxem, 2013).

School buildings also provide information for various groups since school activities also reach students and employees' broader social and family circles beyond the school environment. Knowledge of energy consumption in these buildings can lead to practical actions to upgrade energy efficiency and promote a conscious culture of energy consumption in society. The energy efficiency analysis in buildings is essential for comparing efficiency between technologies and determining consumption patterns. Energy efficiency analysis provides essential information for estimating future consumption and developing public policies on energy efficiency, which improves resource management (Geraldi and Ghisi, 2020).

Energy efficiency is significant in school buildings related to the comfort and air quality conditions inside them, while the energy cost of these buildings is related to their operating costs. Besides, school buildings are different from other buildings because they are places where children are educated and learn how to become environmentally conscious citizens. Therefore, it is crucial that schools set an excellent example of user comfort, energy efficiency, and pollution control. In Europe, there is 
also a steady awareness of promoting sustainability choices among school buildings that entail energy-efficient technologies and measures (Dimoudi and Kostarela, 2009).

An essential cornerstone of sustainable use of energy in school buildings has been achieved through the bioclimatic architecture, as well as interior - exterior - outdoor design based on local climate to support thermal and visual comfort, by using efficiently and sustainably renewable sources of energy like solar, thermal, and wind energy sources. Essential elements of bioclimatic architecture involve passive and low energy schools that save a significant amount of energy, reaching 70\%. Besides, schools with the highest energy efficiency consume up to $50 \%$ less primary energy than new buildings. The results are optimistic because they sustain immense potential for energy savings in municipalities' building sector (Thewes et al., 2014). The buildings of the tertiary sector in which the school buildings are included should not only be friendly to the students satisfying their needs for learning, personal development, and self-realization but at the same time, the energy they consume for their operation should be minimized (Zhang et al., 2017).

The role of energy efficiency is the prime goal for reducing environmental pressures (Skordoulis et al., 2020b). Energy efficiency is also co-existing in alignment with extensive energy-depended organizations and resources depletion. Interestingly, it has been methodologically investigated the empirical association of ethical and transformational leadership in influencing green creativity and eco-innovation in higher educational institutes of Indonesia (Bahzar, 2019). This study denoted that while jointly approaching green transformational leadership, eco-innovation, and green creativity, their significant contribution was proven to enhance energy efficiency in Indonesia's higher education sector. In such developing economies, it is also noteworthy that the central government needs to drive future policies of environmentally-centred innovations that can also target national energy efficiency (Bahzar, 2019).

Concerning renewable energy sources (RES), taught courses are imperative since the social demand for environmental policies has not been strongly linked to environmentally oriented curricula among European countries, while educating the educators should be expanded and intensified (Bojic, 2004). In the relevant literature, such multifaceted benefits of policies can also be incorporated into the taught courses of architecture and technology. Such courses commonly address energy consumption and emissions, rational energy use, environmental impact, high-performance efficiency, and sustainability, all related to the built environment. The content and the learning outcomes of taught courses should be driven to share information and deepen the discussion within the educational community. It is also anticipated that positive environmental sign energy issues can become an integral component of designing and delivering relevant courses (Muraj et al., 2020).

Another noteworthy analysis investigating how European policies motivate energy consciousness among local populations is that of Cotton et al. (2015). Students need to develop energy literacy, finding ways to enhance it using a behaviour change model. Energy literacy among students is a vital part of the "greening" agenda while supporting students to convey their ideas about energy use and energy saving, enhancing their energy literacy through attending formal, or even informal-experiential, curricula of teaching and, subsequently, forming social attitudes of making sustainable energy-related behaviour choices (Cotton et al., 2015).

According to Kyriakopoulos et al. (2020), environmental education can promote energy-saving behaviour. As environmental education among students and personnel becomes stronger, environmental behaviour becomes more positive.

The study of Drosos et al. (2021) revealed a positive relationship between school managers' environmental perceptions and the application of energy-saving behaviour for Greek schools. Furthermore, the school manager perceptions were related to applying energysaving technologies at school units.

In similar studies, it is noteworthy that energy consumption in buildings primarily depends on the building's type and area in alignment with the level of economic activity of the nearby area and the lifestyle to meet the building users (Maleviti et al., 2012). Such human needs of today are linked to energy-intensive appliances and equipment, like those of ventilation and air conditioning systems (Maleviti et al., 2011; Maleviti et al., 2012).

Another approach to investigate the multifaceted effects of campus sustainability planning on annual energy inflows and outflows were deployed in California higher education campus (Petratos and Damaskou, 2015). The evaluation of impact factors on energy outflows and a link between energy outflows and building utilization were based on building utilization data and renewable energy credits (RECs) and aid sustainability management strategies for campus energy conservation and sustainability planning efforts (Petratos and Damaskou, 2015).

Concerning the case of Greece, there are around 17000 school buildings, according to data from OECD (2018). Most of them are rather old with a mean age of around 36.5 years, while a significant part of the buildings (around $30 \%$ ) are over 40 years old. Furthermore, the heating facilities are described as mediocre while the energysaving measures are technologies are just starting to be implemented (Dascalaki \& Sermpetzoglou, 2011).

\section{Methods and Models}

\subsection{Predictive Classification Models}

Classification models are used for performing predictive analytics on specific datasets. Such algorithms use predictive attribute values to assess the classification value. Machine learning classification models are separated into two discrete categories according to the predicted class values. In both categories of the classification process, the predicted values (i.e., classes) are categorical. Specifically, in case the predicted categorical values take only two class values, we are dealing with binary classification, while if there are more than two classes, we deal with multiclass classification. In this paper, we have experimented with both binary as well as multiclass classifiers (Frank et al., 2016). Experimented classifiers are input with a specific set of predictive attributes, while their efficiency is assessed based on particular evaluation methods and metrics. 
Citation: Ntanos, S., Kyriakopoulos, G.L, Anagnostopoulos, T., Xanthopoulos, T., Kytagias, C., Drosos, D. (2022) Investigating the Environmental and the Energy Saving Behavior among School Principals through Classification Algorithms. International Journal of Renewable Energy Development, 11(2), 449-461, doi: 10.14710/ijred.2022.43007 452 ।

\subsection{Evaluation Method and Metric}

\subsubsection{0-Fold Cross-Validation}

We evaluated the examined models with 10 -fold crossvalidation evaluation method, which divides the initial dataset into 10 equal-sized parts and then in a certain loop incorporates the first 9 parts to train the classifier and the remaining 1 to test the classifier. This process is repeated until all the parts are used for training and testing.

\subsubsection{Prediction Accuracy}

We assessed the effectiveness of the adopted classifiers by incorporating the prediction accuracy evaluation metric, $\mathrm{a} \in[0,1]$, which is defined in the following equation:

$\mathrm{a}=\frac{\mathrm{t}_{\mathrm{p}}+\mathrm{t}_{\mathrm{n}}}{\mathrm{t}_{\mathrm{p}}+\mathrm{f}_{\mathrm{p}}+\mathrm{t}_{\mathrm{n}}+\mathrm{f}_{\mathrm{n}}}$

Where, $\mathrm{t}_{\mathrm{p}}$, are the instances, which are classified correct as positives, and $t_{\mathrm{n}}$, are the instances, which are classified correct as negatives. In addition, $\mathrm{f}_{\mathrm{p}}$, are the instances, which are classified false are positives, and $f_{n}$, are the instances, which are classified false as negatives. A low value of a means a weak classifier, while a high value of a indicates an efficient classifier.

\subsection{Attribute Selection Algorithms}

Prediction accuracy is a robust evaluation metric that provides trustworthy outcomes regarding a classification process. However, there are cases where selecting a subset of specific attributes contained in the initial predictive attributes set can provide better or at least the same prediction accuracy results. When this is the case, we use such a subset of predictive attributes to make the classification process more flexible. Specific algorithms are used to define such a flexible classification output based on the impact each selected attribute has with regards to the class attribute (Frank et al., 2016). The output is to provide a purified subset of meaningful attributes, which exploit the associations of inherent data in more depth.

\subsection{Experimental Setup}

We evaluated the given dataset where each instance summarizes data collected for a specific school manager (school principal). Data was collected through a questionnaire applied in an electronic form, during the 1st quarter of 2018. The same research tool was used in a recent research for Greece (Drosos et al., 2021). The questionnaire was sent to school managers ranging from kindergarten level and covering primary and secondary education public schools' units. The number of schools in Greece for 2016 was 16664 units (OECD, 2018). We randomly selected $2 / 3$ of the school units, and we emailed our questionnaire to 10745 schools. We got back 510 completed questionnaires, having a response rate of $5.68 \%$. The demographics of the respondents are presented in Table 1.

\section{Table 1}

School Principals demographics

\begin{tabular}{|c|c|c|c|}
\hline \multicolumn{2}{|c|}{ Variable } & Frequency & Percent \\
\hline \multirow{2}{*}{ Gender } & Male & 250 & $49.0 \%$ \\
\hline & Female & 260 & $51.0 \%$ \\
\hline \multirow{4}{*}{ Education } & $\begin{array}{l}\text { University } \\
\text { Degree }\end{array}$ & 220 & $43.1 \%$ \\
\hline & Master's Degree & 251 & $49.2 \%$ \\
\hline & Ph.D. & 32 & $6.3 \%$ \\
\hline & Other & 7 & $1.4 \%$ \\
\hline \multirow{5}{*}{ Age } & $<30$ & 2 & $0.4 \%$ \\
\hline & $31-40$ & 35 & $6.9 \%$ \\
\hline & $41-50$ & 135 & $26.5 \%$ \\
\hline & $51-60$ & 314 & $61.6 \%$ \\
\hline & $>60$ & 24 & $4.7 \%$ \\
\hline \multicolumn{2}{|c|}{$\begin{array}{l}\text { Average Years of service in } \\
\text { Education }\end{array}$} & \multicolumn{2}{|c|}{24.78 years } \\
\hline
\end{tabular}

When the dataset was created, we used Weka open-source software to examine how a certain classifier and a suitable attribute selection algorithm can be adopted to perform efficient predictive analytics (Frank et al., 2016).

\subsubsection{Experimental Setup Dataset Structure}

We created the dataset by collecting variables concerning users' preferences. The questionnaire included 56 questions (P1 through P56) concerning the perceptions towards RES implementation, energy-saving beliefs, and energy-saving habits in schools. Most questions were measured in the 5-point Likert scale. Those 56 questions were the independent (predictive) variables for this research purpose. Furthermore, there were five questions (C1 through C5) that were considered as the dependent (Class) variables.

The column of "value" represented the number of categories that each question included. The dataset structure was presented in Table 2. Furthermore, in Table 3 through Table 9, the questions in full text were presented concerning the predictive variables (attributes P1-56) and also the dependent (Class) variables C1-C5.

Out of the 518 users, the actual dataset has 510 instances because we omitted instances with missing values. Each instance depicts all the available information of a unique user taking part in the survey. So, we are performing predictive analytics to estimate the class values $\mathrm{C} 1, \mathrm{C} 2, \mathrm{C} 3, \mathrm{C} 4$, and $\mathrm{C} 5$ with the data produced by 510 users participating in the incorporated survey. In addition, each instance of the dataset has 61 attributes; 56 of them were predictive attributes, while the last five depict the class attributes. Class attributes C1, C2, C3, and C4 take five discrete values (i.e., 1, 2, 3, 4, 5), thus performing multiclass classification. Instead, class attribute C5 takes only two values (i.e., 1, 2); thus we experiment with binary classification. The class attributes have been collectively represented in the following Table 3. 
Table 2

Dataset Structure

\begin{tabular}{|c|c|c|c|c|c|}
\hline Attribute & Type & Value & Attribute & Type & Value \\
\hline P1 & Predictive & $\{1,2,3,4,5\}$ & P32 & Predictive & $\{1,2,3,4,5\}$ \\
\hline P2 & Predictive & $\{1,2,3,4,5\}$ & P33 & Predictive & $\{1,2,3,4,5\}$ \\
\hline P3 & Predictive & $\{1,2,3,4,5\}$ & P34 & Predictive & $\{1,2,3,4,5\}$ \\
\hline $\mathrm{P} 4$ & Predictive & $\{1,2,3,4,5\}$ & P35 & Predictive & $\{1,2,3,4,5\}$ \\
\hline P5 & Predictive & $\{1,2,3,4,5\}$ & P36 & Predictive & $\{1,2,3,4,5\}$ \\
\hline P6 & Predictive & $\{1,2\}$ & P37 & Predictive & $\{1,2,3,4,5\}$ \\
\hline P7 & Predictive & $\{1,2,3,4,5,6,7,8\}$ & P38 & Predictive & $\{1,2,3,4,5\}$ \\
\hline P8 & Predictive & $\{1,2,3,4,5\}$ & P39 & Predictive & $\{1,2\}$ \\
\hline P9 & Predictive & $\{1,2,3,4,5\}$ & P40 & Predictive & $\{1,2\}$ \\
\hline P10 & Predictive & $\{1,2,3,4,5\}$ & P41 & Predictive & $\{1,2,3,4,5,6,7,8\}$ \\
\hline P11 & Predictive & $\{1,2,3,4,5\}$ & P42 & Predictive & $\{1,2\}$ \\
\hline P12 & Predictive & $\{1,2,3,4,5\}$ & P43 & Predictive & $\{1,2,3,4,5\}$ \\
\hline P13 & Predictive & $\{1,2,3,4,5\}$ & P44 & Predictive & $\{1,2,3,4,5\}$ \\
\hline P14 & Predictive & $\{1,2,3,4,5\}$ & P45 & Predictive & $\{1,2,3,4,5\}$ \\
\hline P15 & Predictive & $\{1,2,3,4,5\}$ & P46 & Predictive & $\{1,2\}$ \\
\hline P16 & Predictive & $\{1,2,3,4,5\}$ & P47 & Predictive & $\{1,2,3,4,5\}$ \\
\hline P17 & Predictive & $\{1,2,3,4,5\}$ & P48 & Predictive & $\{1,2\}$ \\
\hline P18 & Predictive & $\{1,2,3,4,5\}$ & P49 & Predictive & $\{1,2,3,4,5\}$ \\
\hline P19 & Predictive & $\{1,2,3,4,5\}$ & P50 & Predictive & $\{1,2,3,4\}$ \\
\hline P20 & Predictive & $\{1,2,3,4,5\}$ & P51 & Predictive & $\{1,2,3,4\}$ \\
\hline P21 & Predictive & $\{1,2,3,4,5\}$ & P52 & Predictive & $\{1,2,3,4,5,6,7\}$ \\
\hline P22 & Predictive & $\{1,2,3,4,5\}$ & P53 & Predictive & $\{1,2\}$ \\
\hline P23 & Predictive & $\{1,2,3,4,5\}$ & P54 & Predictive & Number \\
\hline $\mathrm{P} 24$ & Predictive & $\{1,2,3,4,5\}$ & P55 & Predictive & Number \\
\hline P25 & Predictive & $\{1,2,3,4,5\}$ & P56 & Predictive & $\begin{array}{c}\{1,2,3,4,5,6,7,8,9,10,11,1 \\
2,13\}\end{array}$ \\
\hline P26 & Predictive & $\{1,2,3,4,5\}$ & $\mathrm{C} 1$ & Class & $\{1,2,3,4,5\}$ \\
\hline P27 & Predictive & $\{1,2,3,4,5\}$ & $\mathrm{C} 2$ & Class & $\{1,2,3,4,5\}$ \\
\hline P28 & Predictive & $\{1,2,3,4,5\}$ & $\mathrm{C} 3$ & Class & $\{1,2,3,4,5\}$ \\
\hline P29 & Predictive & $\{1,2,3,4,5\}$ & $\mathrm{C} 4$ & Class & $\{1,2,3,4,5\}$ \\
\hline P30 & Predictive & $\{1,2,3,4,5\}$ & C5 & Class & $\{1,2\}$ \\
\hline P31 & Predictive & $\{1,2,3,4,5\}$ & & & \\
\hline
\end{tabular}

Table 3

Class Attributes (dependent variables)

\begin{tabular}{ll}
\multicolumn{1}{c}{ Class (variable) } & Attribute \\
\hline Importance of providing RES oriented education in schools. & C1 \\
Teachers' role towards energy saving at the school environment. & C2 \\
Students' role towards energy saving at the school environment. & C3 \\
Teachers' role in raising awareness on RES. & C4 \\
Energy Upgrading and Energy Saving Actions at school. & C5 \\
\hline
\end{tabular}

\subsubsection{Adopted Classifier}

$\mathrm{J} 48$ tree classifier, (i.e., available in Weka) is adopted to experiment with both binary and multiclass classification models. We assess the prediction accuracy of each classification model to feed an attribute selection algorithm, which will optimize classification results.

\subsubsection{Adopted Feature Selection Algorithm}

CfsSubsetEval attribute selection algorithm, (i.e., available in Weka) is adopted to experiment with $\mathrm{J} 48$ binary and multiclass models. Such an algorithm selects a subset of the initial predictive attributes to perform classification on specific class values, resulting in optimal prediction accuracy values.

\subsubsection{Experimental Setup Parameters}

The experimented parameters of the dataset include the adopted classifier, the attribute selection algorithm, the evaluation method, and the evaluation metric incorporated to assess the proposed classification models, as they are shown in Table 4.

\section{Table 4}

Experimental Setup Parameters and Values.

\begin{tabular}{lc}
\hline \multicolumn{1}{c}{ Parameter } & Value \\
\hline Experimented Classifier & $\mathrm{J} 48$ \\
Feature Selection & CfsSubsetEval \\
Algorithm & \\
Evaluation Method & 10-Fold Cross-Validation \\
Evaluation Metrics & $\mathrm{a}$ \\
\hline
\end{tabular}


Citation: Ntanos, S., Kyriakopoulos, G.L, Anagnostopoulos, T., Xanthopoulos, T., Kytagias, C., Drosos, D. (2022) Investigating the Environmental and the Energy Saving Behavior among School Principals through Classification Algorithms. International Journal of Renewable Energy Development, 11(2), 449-461, doi: 10.14710/ijred.2022.43007 454 |

\section{Results and Discussion}

In the following section, in order to investigate the research questions presented in the introductory section and included in Table 3, we applied the attribute selection algorithm to the $\mathrm{C} 1, \mathrm{C} 2, \mathrm{C} 3, \mathrm{C} 4$ and $\mathrm{C} 5$ multiclass models, resulting in a subset of predictive attributes (variables) for training the selected $\mathrm{J} 48$ classifier. The results are presented in sections 4.1 and 4.2. Furthermore, a discussion on results is raised in section 4.3.

\subsection{C1 to C4 Multiclass Models}

Model C1 evaluated the "importance of providing RESoriented education", in which the selected attributes were that of P2, P11, P15, P22, P27, P28, and P39. The prediction accuracy of the processed dataset for $\mathrm{C} 1$ multiclass model reached the value of: $\mathrm{a}=0.8313$. Model C2 was referred to the "perception of teachers' role towards energy saving at the school environment", in which the associated variables were that of P13, P30, P34, P41, and $\mathrm{P} 53$. In the case of $\mathrm{C} 2$ multiclass model the prediction accuracy was measured as: $a=0.8568$. Model C3 was developed on "the perception of the students' role towards energy saving at the school environment". The procedure located the following most important variables of P13, P30, $\mathrm{P} 34, \mathrm{P} 41$, and $\mathrm{P} 53$, reaching the prediction accuracy of $\mathrm{a}=$ 0.7921, while model C4 was structured on "teachers' role in raising awareness on RES". At this model the corresponding variables were that of P19, P21, P28, P29, $\mathrm{P} 31$, and $\mathrm{P} 43$, having an overall accuracy of $\mathrm{a}=0.7882$. The full interpretation of the variables that were included in each multiclass model, $\mathrm{C} 1$ to $\mathrm{C} 4$, they are represented in Tables 5 through 8 .

\subsection{C5 Binary Class Model}

Model C5 investigated the binary variable (yes/no) concerning the "application of energy upgrading and energy saving actions at school". By applying the attribute selection algorithm to the dataset, the most critical variables were that of $\mathrm{P} 3, \mathrm{P} 5, \mathrm{P} 6, \mathrm{P} 8, \mathrm{P} 10, \mathrm{P} 18, \mathrm{P} 22, \mathrm{P} 27$, P30, P37, P38, P42, P44, P45, P46, P47, P48, P51, and P53. The prediction accuracy was $\mathrm{a}=0.7463$. The variable interpretation of Model C5 is presented in Table 9, while the prediction accuracy results for all the discussed classification models, C1 to C5, are presented in Figure 1.

Table 5

The Questions Surveyed on C1 and their Corresponding Codified Variable Names.

\begin{tabular}{lc}
\multicolumn{1}{c}{ Question } & Variable name \\
\hline To what extent do you know the following forms of RES - Solar Energy & P2 \\
Our main concern should be to encourage energy-saving efforts & P11 \\
Energy savings are not a concern only for the government & P15 \\
Greece has positive conditions to produce Renewable Energy Sources due to its location and climatic & P22 \\
characteristics & P27 \\
In the taught courses, more emphasis should be placed on the issue of renewable energy sources & P28 \\
It is necessary to organize various educational programs in schools on the importance of renewable energy & P39 \\
sources & \\
At school, we use energy-saving light bulbs & \\
\hline
\end{tabular}

Table 6

The Questions Surveyed on C2 and their Corresponding Codified Variable Names.

\begin{tabular}{lc}
\multicolumn{1}{c}{ Question } & Variable name \\
There are not enough energy reserves and there is worry about running out in the future & P10 \\
The use of renewable energy sources is increasing worldwide & P24 \\
I have a role in saving energy in my school & P30 \\
It is necessary to focus on the importance of energy resources and energy saving in in-service educational & P31 \\
programs for teachers & P56 \\
School Unit Operation District & P10 \\
There are not enough energy reserves and there is worry about running out in the future & P24 \\
\hline
\end{tabular}

Table 7

The Questions Surveyed on C3 and their Corresponding Codified Variable Names.

\begin{tabular}{lc}
\multicolumn{1}{c}{ Question } & Variable name \\
\hline There is a need for gradual replacement of conventional forms of energy, & P13 \\
I have a role in saving energy in my school & P30 \\
Turn off the lights when you leave your classroom for a break & P34 \\
Heating methods & P41 \\
School Unit Type & P53 \\
\hline
\end{tabular}


Table 8

The Questions Surveyed on C4 and their Corresponding Codified Variable Names.

\begin{tabular}{lc}
\multicolumn{1}{c}{ Question } & Variable name \\
\hline I am willing to pay more to get clean energy in my home & P19 \\
It is important in the process of globalization to inform citizens about the consumption of renewable energy & P21 \\
sources & P28 \\
It is necessary to organize various educational programs in schools on the importance of renewable energy & P29 \\
sources & P31 \\
There are insufficient programs in schools regarding renewable energy sources & P43 \\
It is necessary to focus on the importance of energy resources and energy saving in in-service educational & P19 \\
programs for teachers & \\
Do You Perform the Scheduled Annual Maintenance of the Heating Systems Every Year? & \\
I am willing to pay more to get clean energy in my home &
\end{tabular}

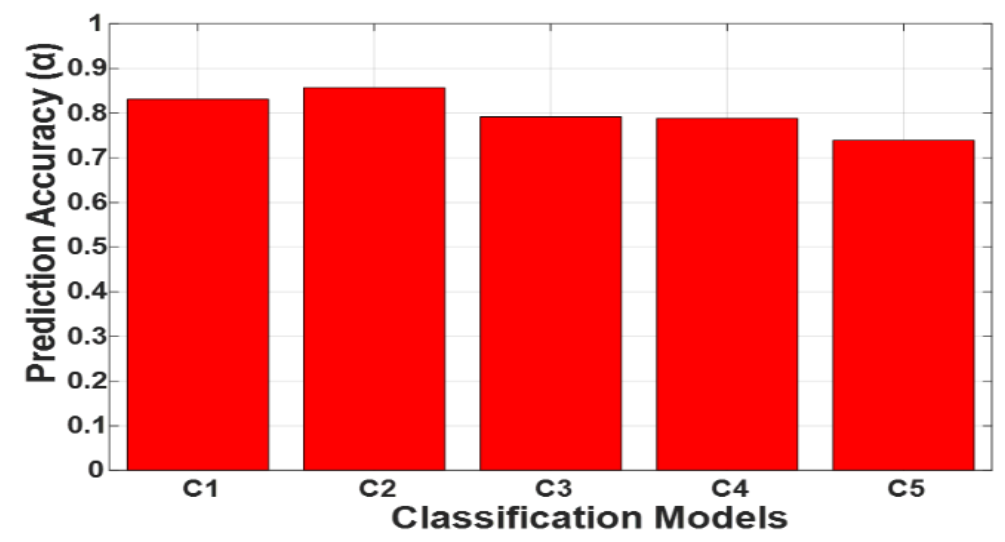

Fig. 1. Prediction Accuracy for the Experimented Classification Models.

Table 9

The Questions Surveyed on C5 and their Corresponding Codified Variable Names.

\begin{tabular}{lc}
\multicolumn{1}{c}{ Question } & $\begin{array}{c}\text { Variable } \\
\text { name }\end{array}$ \\
\hline $\begin{array}{l}\text { Hydrodynamic Energy } \\
\text { Biomass }\end{array}$ & P3 \\
How would you characterize the Use of RES in our Country in Relation to the Countries of the European Union? & P5 \\
The harmonious coexistence of people with the natural environment is a prerequisite for our survival & P8 \\
There are enough energy reserves and there is no need to worry about running out in the future & P10 \\
The development of Renewable Energy Sources in Greece will create energy independence in the long run & P18 \\
Greece has positive conditions to produce Renewable Energy Sources due to its location and climatic & P22 \\
characteristics & P27 \\
In the courses, more emphasis should be placed on the issue of renewable energy sources & P30 \\
I have a role in saving energy in my school & P37 \\
Do you close the windows when the air conditioning is on in the school premises?] & P38 \\
Do you turn off the computer when you leave your office? & P42 \\
Your school has central heating system & P44 \\
Cooling system & P45 \\
Do you perform the scheduled annual maintenance of the cooling systems every year? & P46 \\
Your school has a central cooling system & P47 \\
Do you pay attention to the energy labels that provide information on the energy consumption of appliances? & P48 \\
Gender & P51 \\
Marital status & P53
\end{tabular}


Citation: Ntanos, S., Kyriakopoulos, G.L, Anagnostopoulos, T., Xanthopoulos, T., Kytagias, C., Drosos, D. (2022) Investigating the Environmental and the Energy Saving Behavior among School Principals through Classification Algorithms. International Journal of Renewable Energy Development, 11(2), 449-461, doi: 10.14710/ijred.2022.43007 456

\subsection{Discussion}

\subsubsection{Education attributes of renewable energy among school environment}

It is essential to note the significance of in-field courses taught to built-up the students' environmental awareness. In particular, the role of mixed research methods and outdoor-nature education projects has developed middle school students' appreciation of renewable energy (Buldur et al., 2020). Education of sustainable environmental orientation has been also proven particularly effective to review and revisit study plans of various engineering disciplines and courses taught to senior students in the state of Jordan (Alawin et al., 2016).

Such an in-field education can both support the direct observation on student responses and the modelling of their performance, as well as to support local governments in familiarizing learners with large renewable energy systems distributed among rural areas (Probert, 2011; Strong, 2011) that could maintain regional sustainability through green school education modelling (Novitasari et al., 2019). Such renewable- and energy-related courses are proven the most popular topics among K-12 students in the fields of engineering, physical science, and social science (Stone, 2011).

It is noteworthy that large-scale electricity networks have existed for more than a century, but thousands of primary and secondary schools have no access to electricity, even in our highly industrialized era of living. Therefore, the leaders, the laggards, and the lessons for achieving primary and secondary school electrification are all shaping the geography of energy and education (Sovacool et al., 2016) and its linked issues: global climate change, scarcity of natural resources, and the volatility of the energy marketplace (Favaloro et al., 2017). These courses are interesting for electrification modes among the local communities, residential and urban areas and serve as perfect didactic examples for the school buildings. Such lessons are also interactive between schools that offer renewable-energy programs with companies' demand raised in the small-but-steadily growing industry (Ailworth, 2018).

Another critical environmental and energy courses service is providing quality education to curb societal challenges for sustainable rural development. In this context, the teaching of technical courses should serve:

a) rural schools and remote communities in developing countries through microgrids (Chatterjee et al., 2019)

b) practical implementations to build up knowledge on renewable energy technologies through gaming (Dorji et al., 2015; Spangenberger et al., 2020)

c) the educational provision at offering enrichments programs scheduled for talented high school students (Bayles et al., 2007).

The very end of such a multidisciplinary approach of environmental and energy education is that the realization of renewable energy resources it is the task of the entire society, including students of different ages (Markóczi et al., 2019) and teaching courses (Favaloro, 2017; AlbaFlores and Kirkland, 2018). Not surprisingly, modelling educational curricula for such types of science and technology programs can provide broad scientific coverage of renewable energy through school teaching (Bachmann et al., 2008).

\subsubsection{Education attributes of energy saving among school environment}

The theory of planned behavior was utilized in the relevant literature to examine the influence of different types of information intervention cognition on investigating college students' energy-saving behavior intentions (Yang et al., 2020).

As an essential issue of environmental interest and socioeconomic affection among secondary education students, the impacts of teaching the energy-saving perceptions have been systematically investigated at a similar taught-oriented research study (Ntona et al., 2015).

The taught courses of energy-saving are not always simplistic, but they can contain complex and multivariable analyses. In such an advanced curriculum case, students were familiarized with the notions of residential buildings, energy-saving, and occupants' thermal satisfaction through proper thermal insulation and lighting design (Petidis et al., 2018). Indeed, learners must understand the trace of sun-path to design an energy-saving building. Therefore, saving energy can be better communicated with learners by daylight provision (Sari et al., 2021). The critical point of such an educational approach of natural sciences is to enhance students' environmental awareness of energy-saving behaviors in the built environment since buildings contribute to over one-third of global energyrelated carbon emissions, on which residential occupants' behavior, in this case students' behavior, attains a significant impact (Du and Pan, 2021).

Behavior change energy-saving interventions can motivate pro-environmental behavior in campus residences, being appreciated as a social phenomenon generated by increasing energy demand and financial constraints to invest in green infrastructure. Therefore, literature approaches can report on a pilot program aiming to reduce energy consumption via change behavior after running interventions in educational institutions (Bull et al., 2018). It was proven that information provision of energy-saving tips combined with regular feedback and incentives offered in favour of pro-environmental behaviour can accomplish energy-use reductions in residential zones, resulting in environmental and economic benefits among local education communities (Bulunga and Thondhlana, 2018).

Effective energy education depends on continuing research designed to identify instructional strategies that will prove effective learning techniques, thus enhancing learners' understanding of energy-saving. Such learning techniques relate to idea-centred collaborative knowledgebuilding scaffolds and activities (Hong and Lin, 2019). Another critical issue of energy-saving is instilling learners' awareness on improving quality assurance and forming sustainable strategies through engagement-based teaching and learning processes (Platis and Romanowicz, 2020). Such sustainable strategies are linking energysaving with educational institutions. Behavioral and perception of learners towards energy-related attitudes in the United Kingdom (UK) and Portugal indicated differences between the students' responses, reflecting 
their different national contexts and institutionalized diverse institutional priorities. It was reported that students' perceptions of individual agency and their institution's environmental practices are more robust in the UK, whereas students' sense of collective agency and trust in the government and business are stronger in Portugal. Such compare and contrast studies among different countries, not merely different institutions within the same country, can provide the research background that can be extended for the comparison among other institutions and other countries while encompassing actual energy use in alignment with perceived energy use (Cotton et al., 2016).

The taught lessons on energy-saving serve a plethora of learning outcomes organized in the form of a SWOT analysis and their relevant dimensions, Table 10. Based on the key aspects involved at each SWOT dimension, it can be inferred that while weaknesses and threats should be a reality in some educational, regional contexts, they can be shifted to opportunities and strengths under proper regulatory and behavioural changes, also having the social cohesion and approval of the nearby-to-school buildings social-local communities.

\subsubsection{Discussion on adopted machine learning adopted methodology}

Research effort uses certain methodological assumptions based on: (1) either the adoption of 10 -fold cross-validation instead of leave-one-out cross-validation, (2) inferred classification model behavior in new unseen instance of similar dataset distribution, and (3) possibility to generalize the proposed results to other research where the distribution of the dataset is not known.
Leave-one-out cross-validation method is similar to 10 -fold cross validation. In the leave-one-out crossvalidation method, the main body of the given dataset is used, i.e., all the instances except the current instant, for training the body while remaining a single instance for testing the model. This is an iterative process, which terminates when all the main body of the dataset is used for training and in each iteration, only one instance, i.e., different each time, is used for testing the model's prediction accuracy. Since the leave-one-out crossvalidation method is more time and space complex compared to 10 -fold cross-validation, it is used when there no enough evidence, i.e., not enough instances, to train and test the intelligent models. However, there are many instances in this research effort, i.e., 510 user instances, so 10 -fold cross-validation is an efficient and less computationally expensive method for evaluating the adopted models.

A classification algorithm is an intelligent model, which learns patterns from experience, i.e., stochastic processes. Given enough prior knowledge, adopted intelligent models are able to learn in excellent detail ground truth knowledge and build precise models for future predictions. This is also based on the trends and inherent relations of a given training dataset, which is based on a certain distribution. The degree the model fits well in the given dataset distribution outputs to the degree the model can make optimal predictions given new unseen instances that might follow a slightly similar distribution. An excellent fit to rely on this is that minimizes inherent dataset errors for future predictions, which is provided by the value of prediction accuracy. The higher the prediction accuracy, the lesser the error on input data, which in turn means that unseen data of a similar distribution is well predicted given a certain error threshold.

Table 10

Collective evaluation of research outcomes under the SWOT dimensions.

\begin{tabular}{|c|c|}
\hline SWOT dimensions & Key - aspects involved \\
\hline S - Strengths & $\begin{array}{l}\text {-Associating lower energy consumption with greywater heat recovery systems for students' dormitories to } \\
\text { meet EU environmental regulations and targets (Paduchowska et al., 2019). } \\
\text {-Conceptualizing the traditionally taught entities of energy by jointly adopting different methods of } \\
\text { teaching and examining physics: that of case-based learning and traditional instruction. (Demircioglu and } \\
\text { Selcuk, 2016). }\end{array}$ \\
\hline W - Weaknesses & $\begin{array}{l}\text {-Conditions for the creation of energy-saving competence of students in an undergraduate training } \\
\text { environment (Zeer et al., 2016), in alignment with the socioeconomic development of the local societies } \\
\text { (Zolotukhina et al., 2020). } \\
\text {-Making comprehensive the process of studying a series of other technological-related courses like that of } \\
\text { engineering and technical disciplines at the university (Gilmanshin and Gilmanshina, 2017), especially } \\
\text { among developing economies (Zhao et al., 2019). }\end{array}$ \\
\hline O - Opportunities & $\begin{array}{l}\text { Familiarizing students, even at an elementary level of education, with rational management of energy } \\
\text { through: } \\
\text {-firstly, learning ways and policies of implementing energy-saving practices (Lefkeli et al., 2018), } \\
\text {-secondly, developing software-based instructional media by using data obtained by experts' validation } \\
\text { (Sulistyowati et al., 2019), } \\
\text {-thirdly, manufacturing automation with industrial robots that are specially calibrated to increase } \\
\text { productivity (Farhad et al., 2019). }\end{array}$ \\
\hline $\mathrm{T}$ - Threats & $\begin{array}{l}\text {-Awareness of economic development and prosperity should be responsible for the devastating consequences } \\
\text { of the exhaustion of the planet's natural resources and environmental depletion (Zerinou et al., 2020). } \\
\text { Applicability threats also reside in the need to renovate school buildings towards increasing heat recovery } \\
\text { by using ventilators of novel heat recovery and air conditioning systems of prime energy categories (Wang } \\
\text { et al., 2014a, Wang et al. 2014b). }\end{array}$ \\
\hline
\end{tabular}


Citation: Ntanos, S., Kyriakopoulos, G.L, Anagnostopoulos, T., Xanthopoulos, T., Kytagias, C., Drosos, D. (2022) Investigating the Environmental and the Energy Saving Behavior among School Principals through Classification Algorithms. International Journal of Renewable Energy Development, 11(2), 449-461, doi: 10.14710/ijred.2022.43007 458

Machine learning is an empirical science, which means that a classifier used in a certain dataset with a high prediction accuracy might not be a good fit for another dataset with an unknown distribution. This is the main idea in having more than one classifier to train several models on certain data distributions. However, since data are the basis of data science means it cannot hold a generalization of an emerged model to be applied to more than one distribution. Please note that this is a different case than that we have to experiment with slightly similar distributions, since in case of totally unknown data distribution, stochastic processes and pattern extraction should be learnt from the beginning as a new research study. Actually, this is the notion of empirical science, which cannot provide models that can be generalized without any rational limits.

\section{Conclusions}

This paper explored school principals' perceptions concerning energy-saving measures. To analyze the perceptions, we used four predictive classification models, four multiclass models (from 1=totally disagree to $5=$ totally agree), and one binary class model (1=yes, $2=$ no) to locate the essential variables that determine a school building that has performed energy upgrading and applies energy-saving actions.

According to the classification models, the first multiclass model concerning the "importance of providing more RES oriented education in schools" is mainly motivated by the realization of school principals about encouraging energy-saving actions, the knowledge especially on solar energy, the realization that Greece has favourable climatic conditions to promote RES. The second multiclass model concerning the "of teachers' role towards energy saving at the school environment" is motivated by the realization of the managers about the necessity to organize environmental education programs for the teachers and from the school unit district (location). Schools' principals for school units located in east Macedonia, Thrace and Thessaly have a stronger belief in the role of fellow teachers to support the promotion of energy-saving efforts than schools in the Attica region.

The third multiclass model concerning the "students' role towards energy saving at the school environment" is related to variables such as the school unit type and energy-saving behavior such as turning off the lights when leaving the classroom. Students in lower secondary and upper secondary school are expected to have a more active role according to the school principals' perceptions.

The fourth multiclass model concerning the "Teachers' role in raising awareness on RES" is related to variables such as the existence of educational programs on environment and RES. Therefore, in cases where such programs exist, the teacher's role in raising awareness is more potent according to school principals' perceptions.

The fifth binary class model is essential for our analysis since the dependent variable is the binary variable of whether the school has performed energy upgrades. We discovered 19 explanatory variables, with the most important rotating around the positive environmental beliefs of the school principal and everyday routine actions such as closing the windows when leaving the classroom or turning off the computers. Furthermore, there was a correlation with gender. Schools directed by male principals have performed more energy-saving upgrades than schools with female principals.

According to the results, more emphasis should be put on schools in urban areas such as the Attica region. Also, environmental programs should be more frequently and systematically organized, aided by the state and local authorities, to educate and inform school principals about the new technologies and the specific applications in their school units. Furthermore, emphasis should be put on students in the kindergarten and primary education level since school principals currently disregard their environmental role. Children will be future citizens, and environmental education should be instilled early. Moreover, there is a need to organize educational programs and seminars on environment and energy saving for the school personnel and the teachers to be more active and participate in energy saving.

A limitation of this work is that the adopted methodology of our study was based on the questionnaire applied to school principals. However, future implications of the methodology could also include technical information for the schools' buildings about "applied energy-saving technologies" in order to reinforce the applied algorithmic models.

Funding: The authors received no financial support for the research, authorship, and/or publication of this article.

Conflicts of Interest: The authors declare no conflict of interest.

\section{References}

Acharya, B., Adhikari, S. (2021). Household energy consumption and adaptation behavior during crisis: Evidence from Indian economic blockade on Nepal. Energy Policy, 148, Part B, 111998

Ailworth, E. (2018). Management -- Business Education: Wind, Solar College Degrees Gain Steam - Schools offer renewableenergy programs as demand from companies rises in the small but growing industry. The Wall Street Journal. Eastern edition, 2018-05-03.

Alawin, AA. ; Rahmeh, TA. ; Jaber, JO. ; Loubani, S. ; Dalu, SA. ; Awad, W. ; Dalabih, A. (2016). Renewable energy education in engineering schools in Jordan: Existing courses and level of awareness of senior students. Renewable \& sustainable energy reviews, 65, 308-318.

Alba-Flores, R. ; Kirkland, T. (2018). Research Experience for Secondary School Teachers on Renewable Energy: Design and Implementation of a Small Scale Solar Tracker. Association for Engineering Education - Engineering Library Division Papers, 2018-04-06.

Bachmann, C. ; Tang, J. ; Puffenbarger, C. ; Kauffman, M. (2008). Engineering For Non Engineering Schools: A Hands-On Educational Curriculum That Addresses The Need For Renewable Energy Through Undergraduate Research And Applied Science. Association for Engineering Education Engineering Library Division Papers, 2008-06-22, 13.509.1

Bahzar, M. (2019). Effects of green transformational and ethical leadership on green creativity, eco-innovation and energy efficiency in higher education sector of Indonesia. International Journal of Energy Economics and Policy, 9 (6), 408-414. DOI: 10.32479/ijeep.8372.

Bayles, T. ; Rice, J. ; Russ, G. ; Monterastelli, T. (2007). High School Outreach: A Look At Renewable Energy. Association for Engineering Education - Engineering Library Division Papers, 2007-06-24, p.12.805.1 
Bojic, M. (2004). Education and training in renewable energy sources in Serbia and Montenegro. Renewable Energy, 29 (10), 1631-1642. DOI: 10.1016/j.renene.2004.02.004.

Buldur, S. ; Bursal, M. ; Yalcin E., Nazan ; Yucel, E. (2020). The impact of an outdoor education project on middle school students' perceptions and awareness of the renewable energy. Renewable \& sustainable energy reviews, 2020, 134, 110364 .

Bull, R.; Romanowicz, J.; Jennings, N.; Laskari, M.; Stuart, G.; Everitt, D. (2018). Competing priorities: lessons in engaging students to achieve energy savings in universities. International journal of sustainability in higher education, 19 (7), 1220-1238.

Bulunga, AAL.; Thondhlana, G. (2018). Action for increasing energy-saving behaviour in student residences at Rhodes University, South Africa. International journal of sustainability in higher education, 19 (4), 773-789.

Caldwell, K.A., Vaughn, L.A., Harrod, E., Harrod, J. (2019). Social marketing-enhanced home energy education encourages the adoption of energy-saving practices. Journal of Extension, 57(5), 5RIB3.

Chatterjee, A. ; Brent, A. ; Rayudu, R. ; Verma, P. (2019). Microgrids for rural schools: An energy-education accord to curb societal challenges for sustainable rural developments. International journal of renewable energy development, 8 (3), 231-241.

Cooke, R., Cripps, A., Irwin, A., Kolokotroni, M. (2007). Alternative energy technologies in buildings: Stakeholder perceptions. Renewable Energy 32, 2320-2333.

Cotton, D.; Shiel, C.; Paco, A. (2016). Energy-saving on campus: a comparison of students' attitudes and reported behaviours in the UK and Portugal. Journal of Cleaner Production, 129, 586-595.

Cotton, D.R.E., Miller, W., Winter, J., Bailey, I., Sterling, S. (2015). Developing students' energy literacy in higher education. International Journal of Sustainability in Higher Education, 16 (4), 456-473. DOI: 10.1108/IJSHE-12-20130166.

Dascalaki, E., Kontoyiannidis, S., Balaras, K., Droutsa, K. (2013). Energy certification of Hellenic buildings: First findings. Energy and Buildings 65, 429-437.

Dascalaki, E, Sermpetzoglou, V. (2011). Energy performance and indoor environmental quality in Hellenic schools. Energy and Buildings. 43; 718-727.

Demircioglu, S.; Selcuk, GS. (2016). The effect of the case-based learning method on high school physics students' conceptual understanding of the unit on energy. Asia-Pacific forum on science learning and teaching, 17 (2), 1-25.

Diakaki, D., Grigoroudis, E., Kolokotsa, D. (2013). Performance study of a multi-objective mathematical programming modelling approach for energy decision-making in buildings. Energy, 59, 534-542.

Diakoulaki, D. (2014). Energy sector in Greece in an crisis epoch: Challenges and Perspectives [in Greek] Available at: https://www.hba.gr/5Ekdosis/UplPDFs/sylltomos14/291 304\%20Diakoulaki\%202014.pdf

Dimoudi, A., Kostarela, P. (2009). Energy monitoring and conservation potential in school buildings in the C' climatic zone of Greece. Renewable Energy 34(1), 289-296.

Dorji, U.; Panjaburee, P.; Srisawasdi, N. (2015). Gender differences in students' learning achievements and awareness through residence energy-saving game-based inquiry playing. Journal of computers in education (the official journal of the Global Chinese Society for Computers in Education), 2 (2), 227-243.

Doukas, H., Malamatenios, X., Gkonis, N. (2017). European policies on energy savings and buildings renovation. Energy and Environment [In Greek]. Available at: https://www.alunet.gr/2017/01/4351v3

Doulos, L.T., Kontadakis, A., Madias, E.N., Sinou, M., Tsangrassoulis, A. (2019). Minimizing energy consumption for artificial lighting in a typical classroom of a Hellenic public school aiming for near Zero Energy Building using
LED DC luminaires and daylight harvesting systems. Energy \& Buildings 194, 201-217

Drosos D., Kyriakopoulos G.L., Ntanos S., Parissi A. (2021). School Managers Perceptions towards Energy Efficiency and Renewable Energy Sources. International Journal of Renewable Energy Development, 10(3), 573-584. https://doi.org/10.14710/ijred.2021.36704

Du, J.; Pan, W. (2021). Examining energy-saving behaviors in student dormitories using an expanded theory of planned behavior. Habitat international, 107.

Farhad S.; Kandray Sr DE.; Sinaki MY. (2019). Undergraduate Students' Research on Energy Saving in Industrial Robots: Effect of Regular and Irregular Meetings on Deductive Research. Association for Engineering Education Engineering Library Division Papers, 2019-06-15.

Fateh, B., Zrelli, M.H. (2019). Renewable and non-renewable electricity consumption, environmental degradation and economic development: Evidence from Mediterranean countries. Energy Policy, 133, 110929. DOI:10.1016/J.ENPOL.2019.110929

Favaloro, T. ; Jenkins, BM. ; Lehmann, M. ; Træholt, C. ; Lipschutz, RD ; Kornbluth, KL. ; Isaacson MS. (2017). Setting the Foundations for International and Crossdisciplinary Innovation: The U.S.-Denmark Summer School "Renewable Energy: In Practice". Association for Engineering Education - Engineering Library Division Papers, 2017-06-24.

Frank, E.; Hall, M.A.; Witten. IH. The Weka Workbench. Online Appendix for "Data Mining: Practical Machine Learning Tools and Techniques", Morgan Kaufmann, 4th Edition, 2016

Geraldi, M.S., Ghisi, E. (2020). Mapping the energy usage in Brazilian public schools. Energy and Buildings, 224, 110209. https://www.sciencedirect.com/science/article/abs/pii/S0378 778820302954

Giannarakis, G.; Zafeiriou, E.; Arabatzis, G.; Partalidou, X. (2018). Determinants of corporate climate change disclosure for European firms. Corporate Social Responsibility and Environmental Management. 25(3), 281294.

Gilmanshin, IR.; Gilmanshina, SI. (2017). Competence formation of engineering directions students in the field of energysaving as a way to create new generation technologies. IOP conference series. Materials Science and Engineering, 240 (1), 12022.

Górecki, W., Kotyza, J., Hałaj, E., Luboń, W., Pełka, G., Sowiz Dz Ał, A., Dawiec, D., Smaczna, P., Malik, D. (2020). Education and research in the field of renewable sources of energy in the Centre of Sustainable Development and Energy Savings WGGIOS AGH in Miekinia. E3S Web of Conferences, 154, 07006. DOI: $10.1051 / \mathrm{e} 3 \mathrm{sconf} / 202015407006$.

Gormally, A.M., O'Neill, K., Hazas, M.D., Bates, O.E.G., Friday, A.J. (2019). 'Doing good science': The impact of invisible energy policies on laboratory energy demand in higher education. Energy Research and Social Science, 52, 123-131. DOI: 10.1016/j.erss.2019.02.012.

Hong, H-Y.; Lin, P-Y. (2019). Elementary students enhancing their understanding of energy-saving through idea-centered collaborative knowledge-building scaffolds and activities. Educational technology research and development, 67 (1), 63-83.

Katircioglu, S.T. (2014). Estimating higher education induced energy consumption: The case of Northern Cyprus. Energy, 66, 831-838. DOI: 10.1016/j.energy.2013.12.040.

Kim, A.A., Sunitiyoso, Y., Medal, L.A. (2019). Understanding facility management decision making for energy efficiency efforts for buildings at a higher education institution. Energy and Buildings, 199, 197-215. DOI: 10.1016/j.enbuild.2019.06.044.

Kyriakopoulos G., Ntanos, S., Asonitou, S. (2020). Investigating the environmental behavior of business and accounting university students, International Journal of Sustainability in Higher Education, 210, 819-839. https://doi.org/10.1108/IJSHE-11-2019-0338 
Citation: Ntanos, S., Kyriakopoulos, G.L, Anagnostopoulos, T., Xanthopoulos, T., Kytagias, C., Drosos, D. (2022) Investigating the Environmental and the Energy Saving Behavior among School Principals through Classification Algorithms. International Journal of Renewable Energy Development, 11(2), 449-461, doi: 10.14710/ijred.2022.43007 460 |

Lefkeli, S.; Manolas, E.; Ioannou, K.; Tsantopoulos, G. (2018). Socio-cultural impact of energy-saving: Studying the behaviour of elementary school students in Greece. Sustainability, 10 (3), 737.

Maleviti, E., Mulugetta, Y., Wehrmeyer, W. (2011). Environmental Attitudes and Energy Initiatives within the Hellenic Hotel Sector. R.J. Howlett, L.C. Jain, \& S.H. Lee (Eds.): Sustainability in Energy and Buildings, SIST 7, pp. $225-235$. Available

at: https://link.springer.com/chapter/10.1007/978-3-642-173875_23

Maleviti, E., Mulugetta, Y., Wehrmeyer, W. (2012). Energy consumption and attitudes for the promotion of sustainability in buildings", International Journal of Energy Sector Management, 6(2), 213 - 227. Available at: http://dx.doi.org/10.1108/17506221211242077.

Markóczi RI.; Erzsébet, J. ; Enikő, K. ; Károly, T. ; Judit, UV ; János, M, (2019). Primary and secondary school students' knowledge related to renewable energy and some of its influencing factors. Journal of Baltic science education, 18 (6), 924-942.

Muraj, I., Veršić, Z., Binicki, M. (2020). Sustainability, Environmental Performance and Energy Efficiency in Higher Education: Faculty of Architecture, University of Zagreb. IOP Conference Series: Earth and Environmental Science, 410 (1), 012088. DOI: 10.1088/17551315/410/1/012088.

Novitasari, D. ; Hidayat, S. ; Puruhito, DD. ; Arruzi, RK. ; Aliyah, F. ; Mahfud, A. (2019). An Efforts to Maintain the Sustainability of Renewable Energy System in Rural Area through Green School Education Model. IOP conference series. Earth and environmental science, 353 (1), 12051.

Ntona, E.; Arabatzis, G.; Kyriakopoulos GL. (2015). Energysaving: Views and attitudes of students in secondary education. Renewable \& sustainable energy reviews, 46, 115.

Odyssee-Mure Project (2021) "Energy Efficiency Trends in Buildings", available at: https://www.odysseemure.eu/publications/policy-brief/buildings-energyefficiency-trends.html (accessed 20 June 2021).

OECD (2018). The Greek education system in context, in Education for a Bright Future in Greece, OECD Publishing, Paris. DOI: https://doi.org/10.1787/9789264298750-3-en

Paduchowska, J.; Żabnieńska-Góra, A.; Polarczyk, I.; Piekarska, K.; Danielewicz, J.; Kaźmierczak, B.; Kutyłowska, M.; Jouhara, H.; Sayegh, M.A. (2019). E3S web of conferences, $116,56$.

Pallis, P., Gkonis, N., Varvagiannis, E., Braimakis, K., Karellas, S., Katsaros, M., Vourliotis, P., Sarafianos, P. (2019). Towards NZEB in Greece: A comparative study between cost optimality and energy efficiency for newly constructed residential buildings. Energy and Buildings, 198, 115-137. https://www.sciencedirect.com/science/article/pii/S03787788 19301641 - !

Pereira, L.D., Raimondo, S., Corgnati, P., da Silva, M.G. (2014). Energy consumption in schools - A review paper. Renew. Sustain. Energy Rev. 40, 911-922.

Petidis, I. ; Aryblia, M. ; Daras, Tryfon ; Tsoutsos, T. (2018). Energy-saving and thermal comfort interventions based on occupants' needs: A students' residence building case. Energy and buildings, 174, 347-364.

Petratos, P., Damaskou, E. (2015). Management strategies for sustainability education, planning, design, energy conservation in California higher education. International Journal of Sustainability in Higher Education, 16 (4), 576603.

Platis, MI.; Romanowicz, J. (2020). Integrating Energy Saving Awareness into Student Engagement-Based Teaching and Learning Process. Sustainability, 12 (22), 9626.

Probert, T. (2011). Renewable energy education: PEi goes back to school. Power engineering international, 19 (5), 174

Sari, L H ; Rauzi, E N ; Muslimsyah ; Mahmud, M (2021). Sunpath model as a simple helping tool for architecture students in understanding saving energy building design. IOP conference series. Materials Science and Engineering, 1087 (1), 12017.

Skordoulis, M., Ntanos, S., \& Arabatzis, G. (2020). Socioeconomic evaluation of green energy investments: Analyzing citizens' willingness to invest in photovoltaics in Greece. International Journal of Energy Sector Management, 14 (5), 871-890.

Skordoulis, M., Ntanos, S., Kyriakopoulos, G. L., Arabatzis, G., Galatsidas, S., \& Chalikias, M. (2020b). Environmental innovation, open innovation dynamics and competitive advantage of medium and large-sized firms. Journal of Open Innovation: Technology, Market, and Complexity, 6 (4), 195.

Soares, N., Pereira, L.D., Ferreira, J., Conceição, P., da Silva, P.P. (2015). Energy efficiency of higher education buildings: A case study. International Journal of Sustainability in Higher Education, 16 (5), 669-691. DOI: 10.1108/IJSHE-11-20130147.

Sovacool, BK. ; Ryan, SE (2016). The geography of energy and education: Leaders, laggards, and lessons for achieving primary and secondary school electrification. Renewable \& sustainable energy reviews, 58, 107-123.

Spangenberger, P. ; Matthes, N. ; Kruse, L. ; Draeger, I. ; Narciss, S. ; Kapp, F. (2020). Experiences with a Serious Game Introducing Basic Knowledge About Renewable Energy Technologies: A Practical Implementation in a German Secondary School. Journal of education for sustainable development, 14 (2), 253-270.

Stone, C. (2011). Renewable energy education at the Colorado School of Mines: A survey of development. 2011 Frontiers in Education Conference (FIE), 2011-10, S2H-1-S2H-7.

Strong, SA (2013). The effects of direct observation on student responses in the renewable energy REU program at Colorado School of Mines. IEEE Frontiers in Education Conference (FIE), 985-991.

Sulistyowati, P ; Utomo, D W ; Batlolona, JR ; Saregar, A ; Hudha, M N ; Yusro, A C (2019). Practicing Energy Saving Habits of Elementary Students Through Development of Lectora Inspire Software Based Instructional Media. Journal of physics. Conference series, IOP Publishing, 1381 (1), 12040.

Thewes, A., Maas, S., Scholzen, F., Waldmann, D., Zürbes, A. (2014). Field study on the energy consumption of school buildings in Luxembourg, Energy and Buildings 68, 460-470. DOI: 10.1016/j.enbuild.2013.10.002.

Wang, Y.; Zhao, F-Y ; Kuckelkorn, J.; Li, X-H; Wang, H-Q. (2014a). Indoor air environment and night cooling energy efficiency of a southern German passive public school building operated by the heat recovery air conditioning unit. Energy and buildings, 81, 9-17.

Wang, Y.; Zhao, F-Y.; Kuckelkorn, J. ; Liu, D.; Liu, Li-Qun; Pan, X-C (2014b). Cooling energy efficiency and classroom air environment of a school building operated by the heat recovery air conditioning unit. Energy (Oxford), 64, 9911001.

Yang, R.; Yue, C.; Li, J. ; Zhu, J. ; Chen, H. ; Wei, J. (2020). The Influence of Information Intervention Cognition on College Students' Energy-Saving Behavior Intentions. International journal of environmental research and public health, 17 (5), 1659.

Zeer, E.; Symaniuk, E.; Pecherkina, A.; Stepanova, A.; Symaniuk, N.; Terlyga, N.; Kortov, S.; Balk, I. (2016). The model of creation of energy-saving competence of students of high school. E3S Web of Conferences, 6, 3007.

Zeiler, W., Boxem, G. (2013). Net-zero energy building schools. Renewable Energy 49, 282-286.

Zerinou, I.; Karasmanaki, E.; Ioannou, K.; Andrea, V.; Tsantopoulos, G. (2020). Energy Saving: Views and Attitudes among Primary School Students and Their Parents. Sustainability, 12 (15), 6206.

Zhang, A., Bokel, R., van den Dobbelsteen, A., Sun, Y., Huang, Q., Zhang, Q. (2017). Optimization of thermal and daylight performance of school buildings based on a multi-objective 
genetic algorithm in the cold climate of China. Energy and Buildings 139, 371-384.

Zhao, S.; Song, Q.; Wang, C. (2019). Characterizing the EnergySaving Behaviors, Attitudes and Awareness of University Students in Macau. Sustainability, 11 (22), 6341.
Zografidou, E.; Petridis, K.; Petridis, N.; Arabatzis, G. (2017). A financial approach to renewable energy production in Greece using goal programming. Renewable Energy, 108, 37-51.

Zolotukhina, Y.; Makarova, T.; Dakhin, S.; Prokshits, E.; Zheltenkov, A ; Mottaeva, A. (2020). Motivation of forming professional competences of students in the field of energysaving. E3S web of conferences, 164, 12023.

(C) 2022. The Authors. This article is an open access article distributed under the terms and conditions of the Creative Commons Attribution-ShareAlike 4.0 (CC BY-SA) International License (http://creativecommons.org/licenses/by-sa/4.0/) 